\title{
Innovation Models in Food Industry: A Review of The Literature
}

\author{
Barbara Bigliardi ${ }^{1 *}$, Giovanna Ferraro ${ }^{2}$, Serena Filippelli ${ }^{1}$, Francesco Galati ${ }^{1}$
}

\begin{abstract}
Innovation is considered as one of the main elements of a company success. In recent years, it has assumed a relevant role also in the food industry that was generally defined as a rather mature and slow-going sector. The aim of this paper is to analyse the innovation models applied to the food industry and to carry out a systematic review of the literature. In particular, we overview the most relevant innovation models and identify the main thematic areas discussed in the period from 2016 to 2020 . We also provide recommendations for future research directions.
\end{abstract}

Keywords: Innovation models; food industry; systematic literature review; future research trends.

Submitted: August 31 $1^{\text {st }}, 2020$ / Approved: October $21^{\text {st }}, 2020$

\section{Introduction}

Innovation is recognized as one of the main elements of a company's success. Its role is fundamental in determining higher performance and in ensuring the survival of a company in the market. Generally, any new development adopted by a company is considered innovation.

Innovation can involve creating or re-engineering products or services to meet market demand, introducing new processes to improve productivity, developing or applying new marketing techniques and new forms of management systems to improve operational efficiency. According to Damanpour and Schneider (2009), innovation can be determined by a pressure coming from the external environment especially by the competitiveness, deregulation, shortage of resources and customer demand. For these reasons, a company changes its behaviour and organisation in order to maintain or improve its performance and remain competitive in the market.

In recent years, innovation has also assumed an important role in the food industry that represents the largest manufacturing sector in the European Union (Menrad, 2004; Traill \& Meulenberg, 2002), even though scientific literature has long considered the food industry to be a sector with a low innovative intensity (Christensen et al., 1996; Martinez \& Briz, J., 2000). Indeed, the food industry has generally been defined as a rather mature and slow-growing sector that shows a level of investment in research and development quite low and can be defined as conservative compared to the type of innovation offered to the market (Costa \& Jongen, 2006)

On the contrary, in the last decade the food sector has undergone various social, economic and technological changes which have a relevant influence on the entire food processing chain, from agricultural production, through the processing and distribution of food, to final consumers. Furthermore, the sector is characterized by a more competitive environment that have encouraged considerable changes in the food demand and in the supply chain organization and have lead innovation to be an inevitable activity essential for the success of the companies (Costa \& Jongen, 2006).
For these reasons, the drive towards innovation for companies operating in the food sector is very strong and the academy also agrees in recognizing the important role of innovation in supporting and improving the sector's competitiveness (Capitanio et al, 2010; Grunert et al, 2005; Rama \& Tunzelmann, 2008).

In the past, the food industry was mainly focused on minimizing production costs and paid scarce consideration to customer needs (Bigliardi \& Galati, 2013; Lienhardt, 2004). In the last few years, the sector has shown increasing attention towards the safety and importance of high quality food, as well as towards health, well-being and consumer satisfaction (Aguilera, 2006). A process defined as "chain inversion" has emerged within the sector. This process indicates the important role played by the consumer who indicates to producers his preferences regarding food (Aguilera, 2006). Compared to this turnaround, innovation has assumed a fundamental importance for companies in the sector (Omta \& Folstar, 2005; Traill \& Meulenberg, 2002), allowing the creation of a new assortment of products that meet the changing needs of consumers.

Companies have therefore adopted innovative development processes to create new products. These processes led to the adoption of innovative technological solutions and new business models. Normally, in most food companies these new product development processes are still based on internal innovation. However, a limited but growing number of food industries are developing their new products by adopting some technological solutions from other companies. This highlights the difficulty of some companies in facing and managing innovation internally (Sarkar \& Costa, 2008).

The purpose of this paper is to analyse the innovation models applied to the food industry carrying out a systematic review of the literature. In particular, we discuss about different innovation models such as: the linear model, the push and pull models, the Stage and Gate model and the open innovation model. Through the comprehensive review of the extant literature, the paper aims to achieve two objectives: identify the main thematic area discussed in the selected period 2016-2020 and keep track of their evolution over time, and provide recommendations for future research opportunities.

1) Department of Industrial Engineering, University of Parma, Parma, Italy

2) Department of Enterprise Engineering, Universidad de Roma Tor Vergata, Italy

${ }^{*}$ Corresponding author: barbara.bigliardi@unipr.it 
The methodology used is that of the systematic review which was preferred over that of the traditional review since while the former follows a rigorous, replicable, scientific and transparent process (Cook et al., 1997), the second is often subjective and therefore difficult to verify. The main objective of the systematic review is to provide a scientific contribution regarding the investigated matter. Carrying our this review therefore, means limiting systematic errors, strengthening the legitimacy and authority of the resulting evidence and finally providing more reliable results on which to draw conclusions and make decisions. In particular, we consider the two fundamental steps of the systematic review: firstly the selection of the inclusion criteria and, secondly, the strategy of identification and selection of potential studies.

The paper is organized as follows. Section 2 offers an overview of the main innovation models, Section 3 describes the applied methodology, Section 4 describes the performed analysis and the future research directions, Section 5 gives the conclusions and the final remarks.

\section{An overview of the main innovation models}

In this section, we offer an overview of the main innovation models proposed by the scientific literature. Understanding innovation as a process is very important because it defines how we manage it. This understanding has changed a lot over time.

Early models saw innovation as a linear sequence of functional activities. The linear model of innovation represented one of the first frameworks for understanding the relation of science and technology to the economy (Godin, 2006). In particular, the first discussion of such a model came from Holland (Holland, 1928) that suggested to increase the development of the industries reducing the "time lag" between discovery and production through the investment in research. Holland identified a sequence of successive stages: pure science research, applied research, invention, industrial research (development), industrial application, standardization and mass production.
Almost ten years later, the first complete description of this model came from Stevens, the vice president at Arthur D. Little and it was published in 1941 (Stevens, 1941). According to this model, innovation starts with basic research, then enhances applied research and development and finishes with production and diffusion. The author recognised different stages such as fundamental research, applied research, test-tube or bench research, pilot plant, production, improvement, trouble shooting, technical control of process and quality through which research develops towards the adoption of results in the industrial sector. It is evident that the third and the fourth stages correspond to what we now call development.

Notwithstanding its extensive use, the linear model was extremely criticised for its simplicity (Price \& Bass, 1969; Myers \& Marquis; 1969). Recent efforts to modify or replace the model have been limited with regards to its impact.

Further evolutions of the linear model considered the new opportunities arising out of research that rise to applications which found their way to marketplace, the technology push model, or the market needs for something new which then drew out new solutions to the problem, the demand pull model.

Technology push is a linear model adopted from the 1950s to the mid-60s. It considers a scientific discovery, called the push idea, which acts as the engine for a new technological solution. The push idea originated from an individual with the knowledge and imagination is able to transform an idea into an innovation. In other words, the technology push model emphases the importance of technology development as a driving force that precedes the market demand. Therefore, it is not the market that gives rise to the technology push approach, but each new scientific opportunity that evolves into applications and improvements which ultimately find a place on the market. This concept is represented by Figure 1 that shows the technology push model.

Figure 1: The technology-push innovation model.

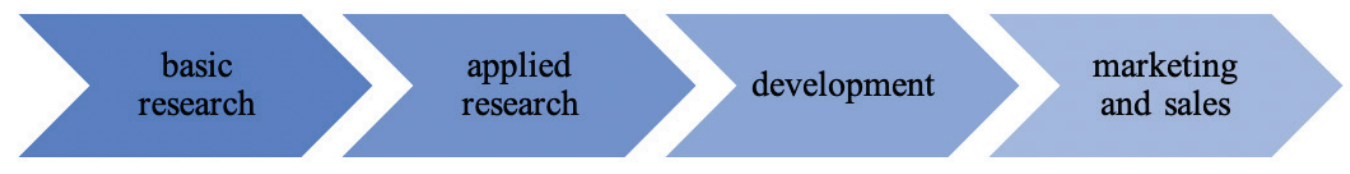

On the other hand, part of the literature considers that it is the market demand that determines the technological development. In this case, the research and development activities are carried out by the scientists as a consequence of what the consumers require from the market (Mowery \& Rosenberg, 1979).

From the second half of the 1960s to the end of the 1970s, the demand pull approach was the most popular in the economic and industrial sector. In this case there is an inversion of the process, in fact the marketing, which in the technology-push occupied the final phase, becomes the starting point of the model and it is as relevant as the research and development sector was in the technology push model. In the demand pull model, the identification of the market needs by production units is crucial, these needs will be then met through technological innovations. Consumers express their preferences regarding the characteristics of the goods they desire, while producers learn, through variations in demand and prices, the preferences revealed by consumers. From here begins the innovative process that leads to placing new and / or improved products on the market. 
The model is based on the belief that there is the possibility of knowing, before the innovation takes place, the direction in which the market is attracting the innovative activity of the producers. Figure 2 depicts the demand pull model.

Figure 2: The demand-pull innovation model.

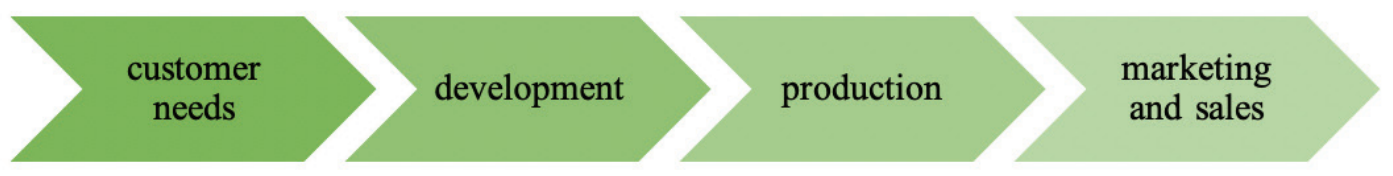

Despite the widespread use, the linear model has highlighted some limitations. In the early 1980s it was increasingly difficult to split a single linear path in the innovation process. It was difficult to define the beginning and the end of the phases of the evolutionary process, since these being unidirectional and sequential do not take into account the feedback (Choi, 2018). Furthermore, sometimes innovation involves false starts, recycling between stages, dead ends and jump out of sequence.

Thus, the two models are no longer able to represent the complexity of innovative phenomena in the current economic and social scenario. Another innovation model is the so-called stage-gate model (Cooper, 1994). It is applied to the development of projects whose purpose is to improve the efficiency and effectiveness of an existing product or to design a new one with certain properties.

The model, also known as the phase-gate model, divides the innovation process into main stages, alternating four control moments (gates). The former specify the objectives, the main activities and the real or intangible object that is produced, while the gates act as a control over the work done in the previous phase. At each gate, information is required that allows to move on to the next phase, if the review of the project does not have a positive result, it is possible to continue on the same phase until the problem is solved. These specify the decisions to be made, the organizational roles involved in the decisions and all the actions to be taken later. The original model is made up of five phases, as depicted in Figure 3, whose modifications or phase changes are often difficult and expensive. These are:

1. Set the goal: the relevance of the idea is assessed and through a quick preliminary investigation the feasibility and its possible competitiveness on the market is analyzed. At this stage it is common to resort to desk research.

2. Development of the Business Case: implies a more in-depth research in order to identify the customer and the end user requirements. The goal of this phase is to develop a plan for the project and define and justify the product.

3. Development: focused on new product design and preliminary tests regarding potential customers. In addition, the production plan and the market launch plan are prepared.

4. Test and validation: during which various product tests are carried out in the laboratory, in the factory and on the market. The market launch scenarios are also approved.

5. Launch. Start of full production, marketing and sales. The product finally enters the market. Quality monitoring operations and any post-launch reviews also belong to this stage.

Figure 3: The stage-gate innovation model.

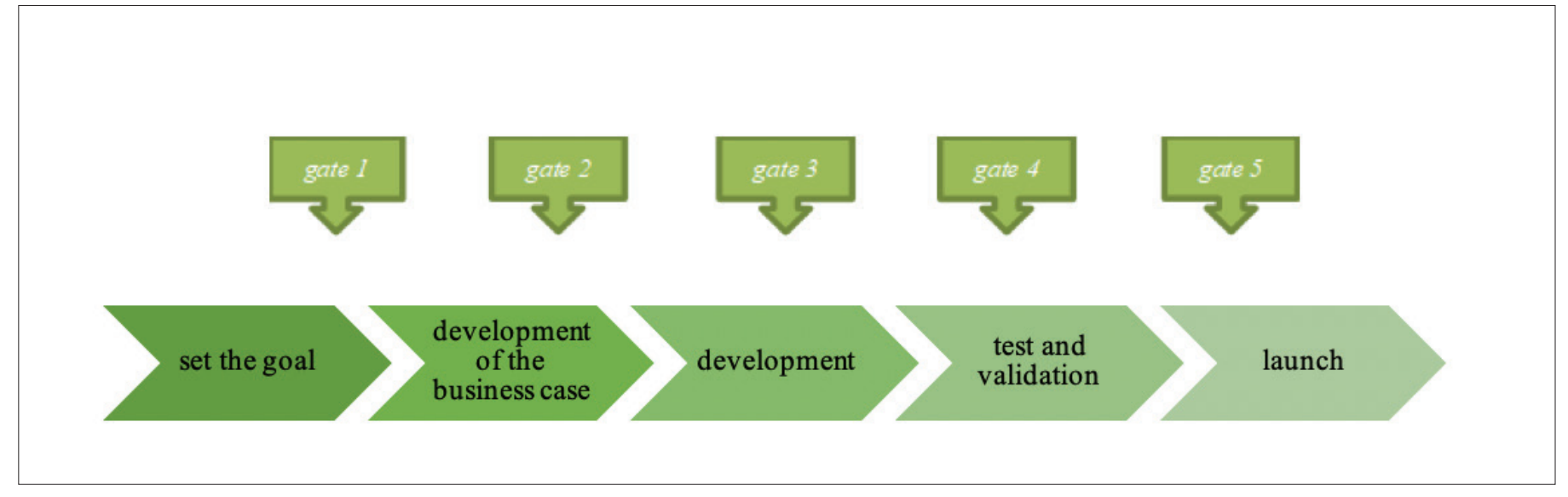


In a more modern version of this model (Cooper, 2014), a discovery phase zero has also been added in which staff members consider the opportunities on the market and brainstorm on new possible ideas. The strength of this method is to be able to improve the company's skills in converting innovative ideas into practical applications and new products. A well-organized innovation process can increase the speed of product development and generate a continuous flow of innovation that allows to offer new products on the market creating a competitive advantage.

However, the stage-gate model is also characterized by a rigid sequence. In particular, it does not consider how innovative ideas are generated and situations in which innovation spreads in multiple and divergent progressions.

Chesbrough (2003) was the first to introduce the concept of open innovation defining it as "both a set of practices for profiting from innovation, and also a cognitive model for creating, interpreting and researching those practices". He described open innovation as "the use of purposive inflows and outflows of knowledge to accelerate internal innovation, and to expand the markets for external use of innovation, respectively" (Chesbrough et al., 2006).

The concept of open innovation is based on the idea that, in the current competitive environment in which companies operate, the linear model of innovation is no longer capable of adequately explaining innovation activities (Bigliardi et al., 2020).

The new paradigm offers a new viewpoint regarding external collaboration, it emphasizes when a simple collaboration evolves into an open innovation relationship. A company can follow an open innovation attitude in three diverse means. It can employ incoming open innovation activities that are able to improve its skills and knowledge by combining suppliers, customers or other actors into the internal innovation activities (Enkel et al, 2009). Otherwise, the company can undertake outward open innovation activities as for example, technology licensing and earning profits by patents (Lichtenthaler, 2008). Lastly, the company can implement a combined open innovation approach by merging the other two approaches (Enkel et al, 2009).

Figure 4: The open innovation model.

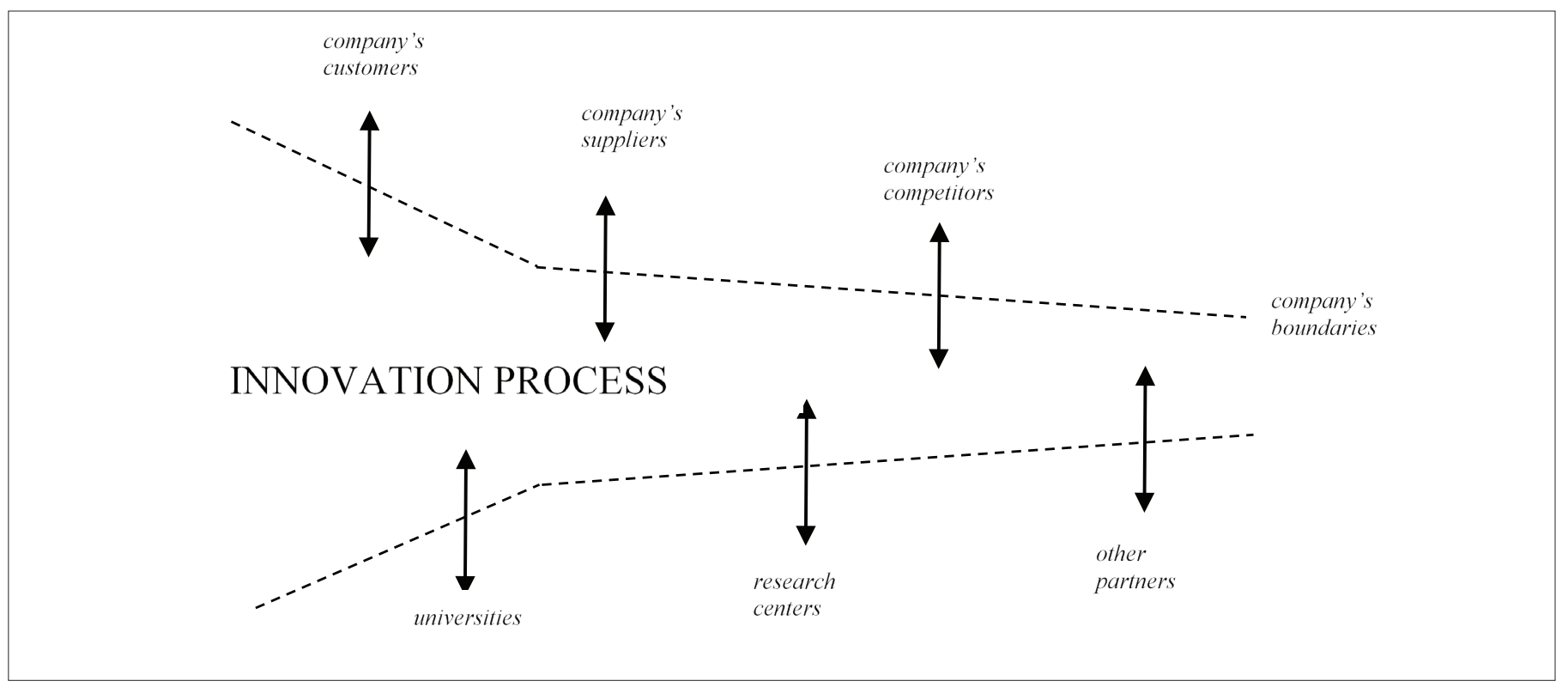

In general, open innovation approach involves an extensive use of internal and external sources to reach different innovation opportunities integrating such practice with the company skills and resources and exploiting the diverse opportunities in various ways (West \& Gallagher, 2006). The adoption of an open innovation approach is strictly linked to the company awareness of its knowledge and management. The relevant knowledge can be internal or external to the company. In the last case, managers should have the capacity to detect, identify, catch and manage outward knowledge and be able to decide the most suitable way to integrate it in the innovation process (Wallin \& Von Krough, 2010). Companies that are not capable to use external knowledge, usually, are not able to compete efficiently in the market (Desouza et al, 2005). Thus, they recur to partnerships with other business partners such as technology providers, suppliers and competitors. However, when a company adopts an open innovation approach, it can pay insufficient attention in protecting its knowledge (Galati et al. 2019) making it vulnerable respect to various risks. This behaviour can have a negative impact on its competitive advantages and its sustainability in the long period. Hence, knowledge sharing represents one of the principal risk of open innovation and for this reason, some companies often prefer to not adopt the open innovation approach because they do not want to lose the control on their internal knowledge.

Within the open innovation literature, several models exist and have been applied to the food industry. The Connect and Develop 
model, for example, has been proposed in 2006 by Huston and Sakkab (2006). This model defines the problems to be solves and make them circulate in global networks of individuals and institutions to find out if someone in the world already has a solution. The Sharing is Winning model (Traitler \& Saguy, 2009) enables the co-creation of innovation and value through partnerships. As stressed by Bigliardi and Galati (2013), this model can be regarded to as a collaboration model extending the definition of open innovation to co-innovation. Bigliardi et al. (2010) proposed in their study the so called "FoodMachinery Framework", that is one of the most adopted in the food machinery industry, stressing that each player in the supply chain perceives innovation as a key factor for survival in now highly competitive markets and therefore participates actively in the open innovation. The Living-lab open innovation model (Wolfert et al., 2010) consists in a new method to organize the integration of information in the food and agriculture sector through a structure that accompanies the project and its implementation. Garcia (2011) proposed the "Want, Find, Get, Manage model", a four-stages model determining how and when external knowledge is required and used in the innovation process and involving all the actors of the food open supply chain. The Value CoCreation open innovation model (Martinez, 2014) is based on a joint process of value creation through consumers who have an active role within an open innovation-oriented corporate strategy. The Consumer-centric open innovation model (Tsimiklis et al., 2015) represents a clear example of crowdsourcing. It was proposed as a new ICT-based framework that incorporates the end consumer in the innovation process. Specifically, consumers' inputs, priorities, and needs drive the innovation process, and are expressed by means of social Websites, Intranets, and blogs. The same ICT means are also used to ask other actors (i.e., suppliers, retailers, distributors, and firms' employees) for new ideas. Finally, more recently a new open innovation model for NPD in the food industry was described (Grimsby \& Kure, 2019) based on the crispbread case. This case may be an example of successful open innovation through the export of agriculture-based products from a country with highly subsidized agriculture and one with the highest labor costs in the world.

\section{The methodology used for the review}

This section describes the methodology used for the systematic review of the innovation models in food industry that we carried out.

\section{The inclusion criteria}

In the performed review, we applied the following inclusion criteria to select the sources of the systematic review:

- Scientific papers in which the terms "innovation model" and

"food" appear in the title, abstract or keywords;

- Scientific papers written in English;

- Scientific papers such as: articles, reviews, conference papers, book chapters or notes publishes in scientific journals or conference proceedings;
- Publications occurred in the period from 2016 until 2020.

- We use the reported inclusion criteria in order to find the sources of the systematic review on the main databases (i.e., ISI Web of Science, Scopus and Science Direct).

\section{The sources selection and database}

The strategy used for the selection of sources in the systematic review has developed over several stages. Initially, a computerized search was carried out within the databases using the key terms: "Innovation model ${ }^{*}$. In this way the sources obtained were 2369 . The next step was to enter the keyword "food" in the search, obtaining 97 articles. Finally we limited our research to sources that were articles, reviews, and conference papers published in scientific journals or conference proceedings written in English. We selected a total number of 94 significant sources, some of which had to be excluded because duplicates or not available and not pertinent. A total of 36 documents was thus included in the review. Table 1 summarises the sources selection.

Table 1: Selection criteria for the articles considered in the review carried on Scopus and Google Scholar database.

\begin{tabular}{l|c|c|c|c}
\hline & WOS & Scopus & Science direct & total \\
\hline $\begin{array}{l}\text { "Innovation model*", } \\
2016-2020\end{array}$ & 533 & 674 & 1162 & 2369 \\
\hline "food" & 13 & 80 & 4 & 97 \\
\hline english & 13 & 77 & 4 & 94 \\
\hline total & \multicolumn{3}{|c}{94} & \\
\hline $\begin{array}{l}\text { without duplicates, } \\
\text { not available or not } \\
\text { pertinent }\end{array}$ & \multicolumn{3}{|c}{36} & \\
\hline
\end{tabular}

\section{The performed analysis}

The selected articles considered in the review have been studied in order to classify them taking into account the document typology and the related content. All 36 articles have been analysed and classified according to the title, document typology, year, abstract and keywords. Taking into account the document typology, Figure 5 shows the classification of the articles according to the document typology. $58 \%$ of the analysed documents are scientific articles, $17 \%$ are book chapters, $11 \%$ are conference papers, $11 \%$ are reviews and only $3 \%$ are notes. The majority of the analysed documents have been published in the last years of the period under investigation, thus stressing the increasing relevance of this issue.

Concerning the keywords, in our analysis we consider the words more cited in the documents to identify the focus of the source content. In addition to "innovation", "food" and "open innovation", the other most cited keywords were "development", "R\&D", "sustainability" and "food industry". It is therefore evident that today the theme of innovation in the food sector also involves dealing with topics such as development and sustainable research. Other relevant keywords, although less frequently mentioned, were "agriculture", "technology", "value chain" and "supply chain". 
Through the analysis performed and the selected keywords, some macro-classes have been identified that group the 36 analysed documents. These macro-topics have been chosen in order to deepen the theme of innovation used in the food sector. Such topics are: the comparison between open innovation and linear models, with particular attention to Italy and to some other European countries that are relevant in the food industry, sustainability and, future trends.

Figure 5: Graphical representation of the articles' classification according to the document typology.

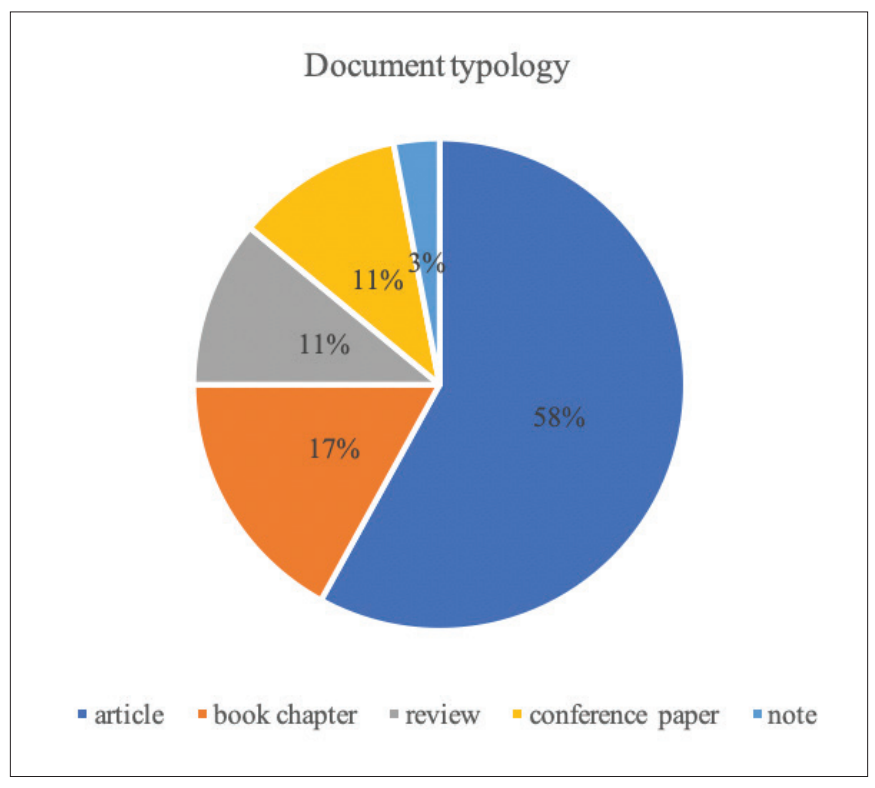

4.1 The comparison between open innovation and linear models

From the analysis carried out, the innovation in the food industry is characterized by factors that concern both the specific internal characteristics and the aspects relating to the context and the network of horizontal and vertical relationships in which the company is included (e.g., Sodano, 2019). These factors influence the decision to innovate or not and the type of innovation to be implemented. An important element in successfully developing and introducing a product innovation is, for example, the ability to build lasting and competitive relationships on the product markets as in the case of the distribution sector, thus confirming the importance of acquiring network capacity to reduce, for example, the costs of distribution chain or to reduce the costs of raw materials (e.g., Galati et al., 2019).

It can be said that, while large companies operate in a "prospector" orientation, SMEs have a "defender" or "reactor" orientation (e.g., Distanont \& Hongmalai, 2018). Only a limited number of SMEs can successfully innovate and they are the ones that follow the Open Innovation model in which $\mathrm{R} \& \mathrm{D}$ is at the center of the innovative process and the most of the funds are invested in it.

An example of how traditional models are still sustainable within the food industry is reported by the case study concerning Lindt \& Sprüngli, a multinational company specialized in the production and sale of confectionery products and in the production of luxury chocolate (Manzini et al. 2017). The article gives a contribution to the debate which aims to understand whether Open Innovation is truly the only model to be adopted to obtain a competitive advantage. It also discusses how the context of factors, such as a company's strategy and its technology, can influence the management of innovations and in particular the approach through the choice of a closed or open innovation model.

More precisely, when a company's strategy is based on excellent internal skills and competences not bound by intellectual property protection mechanisms, as well as patents, trademarks or designs, and when innovative products and processes are based primarily on innate skills in personnel, a traditional approach can be more convenient and can positively influence company performance.

The Lindt \& Sprüngli case demonstrates how choosing a closed model in the era of Open Innovation does not necessarily mean avoiding any type of external collaboration. This requires the adoption of some "countermeasures" to remain competitive against the competition such as substantial investments in staff training and close collaborations that avoid the waste of time required to search for new materials and thus reduce the time to market.

However, as a result of our analysis, we have noticed that the open innovation model is particularly used in the food industry (e.g., Bigliardi et al., 2019; Grimsby \& Kure, 2019; Long \& Blok, 2018).

We also noted that the transition from traditional to open innovation models is mainly due to several reasons including a growing dialogue between academia and food industry, the adoption of new models of intellectual property, and the assignment of a key role to management that allows driving towards innovation process (e.g., Bayona-Saez et al., 2017).

The adoption of the open innovation model has led to significant changes in the entrepreneurial behaviour of the food industry (e.g., BayonaSaez et al., 2017). Companies benefited from access to new skills and profited from the sharing of costs and risks associated with the innovation process, and from the reduction of time to market. There was also a greater focus on the creative processes developed within the companies, that led to an increase of the range of products offered to the market and to a strict monitoring of the technology changes.

In particular, the increase in competitiveness and the longer duration of the competitive advantage are considered the most important drives towards the adoption of the open innovation model (e.g., Caiazza et al., 2019; Galati et al., 2019). The driving forces behind innovation in the food sector are identified both in the internal and external dynamics of the companies. On the one hand, the sector is sensitive to competition with new competitors from emerging countries and to the new tastes of consumers who request high-tech products; on the other hand, endogenous dynamics seem to assume an increasingly important role in defining the strategic behaviour of companies.

In Italy, the food industry ranks second in the manufacturing sector, with 385000 employees and 56500 companies belonging to it. The 
market is one of the most competitive in Europe, essentially due to the lower labor costs which is combined with a greater capacity for market penetration by products from other countries. In this context, innovation, which is reflected in a process, a product or in the internal organization, is a strategic element through which a company can improve its competitiveness on both national and international markets. For this reason, a higher qualification of human capital, a clearer orientation towards high quality products, organizational changes and the development of relationship skills are factors that should be considered in a successful company (e.g., Hullova et al., 2016). When product and process innovations are considered separately, the same factors can take on a different role and specific characteristics can lead to a different type of innovation. In general, the role of market orientation could be considered directly or indirectly linked to the characteristics of the customers demand (e.g., Galati et al., 2019). When the demand or preference for high quality becomes stronger, the propensity for innovation increases. Furthermore, internal organization characteristics, such as the quality of human capital, are also taking on an increasingly important role for Italian food companies in the development of new products (e.g., De Martino \& Magnotti, 2018).

On the contrary, innovation of internal processes seems to be more related to the financial structure and size of food businesses, confirming that technological changes in this sector are mainly related to the possibilities of companies to invest in new technologies developed by upstream industries and also that process innovation occurs mainly through investments in equipment and capital goods (e.g., De Martino \& Magnotti, 2018).

Regarding Europe, some interesting cases emerge from the study of the analysed sources. For example, in the United Kingdom, SMEs in the food sector are more focused on incremental than radical innovation and are mainly engaged in product and process innovations rather than in those relating to packaging and positioning (e.g., Trott \& Simms, 2017).

In the case of Germany, the food industry, which is one of the main sectors of the national economy with a high relevance for employment and economic production, is traditionally considered to be a research-intensive sector, although the innovations intended as new products, processes or services are an important tool to stand out from the competition and meet consumer expectations. In recent years, the focus of the innovation activities of the German food industry has shifted from being a sector that depends heavily on technological developments in the supply industries, towards a demandoriented model that launches a large number of new or new food products improved, often combined with process innovations (e.g., Ciliberti et al., 2017).

This new orientation of the food sector is underlined by company surveys in which the aspects of the market and demand are the most important prerequisites for successful innovations. Obviously, there are still significant implementation deficits, particularly in small and medium-sized enterprises, but in this regard there is a high potential for improvement in the coming years.
As far as studies developed in France are concerned (e.g., BayonaSaez et al., 2017), demonstrated that each category of employment can be involved in the innovation process and in its different phases: concept phase, decision and implementation. The size of the company is related to the propensity for innovation. At the same time, some more original factors appear, such as the influence of company status: after having controlled sectoral influence, in fact, French cooperative companies seem to innovate less than private ones.

In France, innovation is considered as a multiphase process in which the relative importance of each phase largely depends on the type of innovation considered. The concept phase of a product turns out to be the most important phase in the case of radical innovation, which above all involves highly qualified work categories such as employees or R\&D engineers. At the same time, the implementation phase, which seems to be particularly important in the case of incremental innovation, underlines the role of knowledge of the intermediate categories. In general, small companies seem to be less innovative for two main reasons: the most common motivation regards the effect of the economy of scale which is correct only in the case of process innovation in relation to the level of capital intensity, in case of radical innovation due to their work structure and in particular due to the lack of dedicated staff in the R\&D unit.

An interesting aspect that emerges in Spain is that concerning public funding: food companies that have received national funds have invested almost 54\% more in R\&D than companies without the public support. In addition, it has been noted that $\mathrm{R} \& \mathrm{D}$ expenditure for product and organizational innovation are more relevant than that invested for process innovation (e.g., Alarcòn \& Arias, 2018).

In Hungary, the food industry is the leading manufacturing industry. However, its level of R\&D spending is lower if compared with other European countries. Török et al. (2019), studied the demand pull innovation in Hungarian food sector, and specifically they investigated the innovation of Hungarian SMEs and the determinants of innovation production function. Their study showed that, on the one hand, disciplinary knowledge does not play a significant role in market innovation, while newly generated tacit knowledge, coming mainly from their food chain networks, is very important.

\subsection{Sustainability}

The socio-economic changes of recent decades, in a context of globalization of markets and renewed environmental and food safety problems, have led consumers to greater sensitivity which is reflected in more informed purchases. In this constantly evolving scenario, agrifood companies have put in place numerous efforts to introduce new strategies and paradigms in their business approaches.

The technologies developed in the field of genetics, new materials and communication have in fact revolutionized the way in which food is produced, marketed and consumed (e.g., Dawson et al., 2019). The idea of food has changed, going from that of a banal consumer good needed to satisfy basic human needs, to that of a product closely related to human health, environmental conservation, social justice and development of new economic activities. 
Even if sustainability and innovation, are contested and controversial concepts (Rauter et al., 2017), according to Franceschelli et al. (2018), innovation in the food industry is the panacea for sustainable development, and plays a key role in fostering sustainability in company activities. Indeed, currently, innovation in the food system has the task of facing the two main major challenges of our time, namely to protect the environment and achieve global food security (e.g., King et al., 2017). For this reason, in recent years the debate on innovation in the food sector has been increasingly associated with the problem of sustainability (e.g., Saguy, 2016; Emamisaleh et al., 2018; Franceschelli et al., 2018; Rabadan et al., 2019; Stanco et al., 2020). Innovations contributing to sustainability are called sustainability-oriented innovations (e.g., Rauter et al., 2017). They can also be referred to with terms such as sustainable innovations, eco-innovations, green innovations, and so on. The need for collaboration lead to the concept of open innovation for sustainable innovations (e.g., Bigliardi \& Galati, 2016). Sustainable innovation to be developed often requires food companies to deal with different kinds of knowledge thus requiring the involvement of external partners (e.g., Rauter et al., 2017).

In addition, among all the industries, the food one has made significant changes and developed business model innovations taking into account environmental issues (Vrontis et al., 2016; Bresciani, 2017). For example, Bossle et al. (2016) stressed that food firms engage in eco-business model innovation driven by internal (i.e., the human resources or environmental capability) as well as external factors (i.e., collaboration or environmental regulations). Similarly, Ulvenblad et al. (2019), investigating companies in the Swedish agri-food sector, stressed that, being under increasing pressure to adopt sustainable business models that consider economic, social and environmental aspects, they adopt sustainable business models to innovate their businesses.

\subsection{Future Trends}

The innovation models used by the food industry indicate that the sector is moving towards open models focusing on the acquisition of external knowledge and on the ability of the companies to adapt themselves to socio-economic and institutional changes (e.g., Bayona-Saez et al., 2017). The open innovation models can represent a complement to more traditional models (Galati et al., 2016). In the coming years, the sector will face new challenges arising from new technological opportunities. The food industry could focus on new processing techniques taking advantage from the latest discovery in biotechnology (e.g., Saguy et al., 2017) or devote a part of production on functional foods to offer customers a range of increasingly new and cutting-edge products (e.g., Santelamo et al., 2018). For example, the use of nanotechnologies represents an important opportunity for the food sector which however requires significant investments by companies towards research and development (e.g., He et al., 2019).

Furthermore, the use of new communication and information techniques is expected to acquire new markets (e.g., Cillo et al., 2019; Santoro et al., 2019). Similarly, the use of new transformation and packaging techniques for the products is envisaged such as, for instance, the use of high pressure technology, for modified atmosphere or aseptic packaging (e.g., Ekezie et al., 2017; Majid et al., 2018).
Finally, an important emerging application of open innovation in the food industry refers to traditional food products (Bigliardi, 2019). Indeed, as stressed by Bigliardi (2019) in her study, producers of traditional food products are mainly SMEs that as a consequence of their dimension are facing increased competitive pressure. These companies may face this pressure through an open innovation approach.

\section{Conclusion}

The paper analysed the most common innovation models and what emerged is that, according to the opinion of recent scientific research on innovation, we are today in the era of open innovation, that is, companies almost never innovate on their own, but their innovation activities are integrated in a network of different actors and in "institutional" frameworks.

The systematic review of the extant literature shows that despite these premises, the food industry is still linked to linear innovation models. Today, it is clear that innovation models are influenced and influence external factors. Over time, it has been understood how relations with the outside world can positively influence the company's performance and for this reason it is believed that the approach that should be adopted in the food sector is that of greater openness. Open innovation models should complete the shortcomings that emerge in the more traditional and hitherto functioning models, so as to strengthen weaknesses and establish an exchange of knowledge where necessary.

Taking into account the European countries, and in particular Italy, where the food industry occupies the second place in the manufacturing sector, an increase in funding for research and development is expected. In fact, in a dynamic market such as that of the food sector where more and more attention is paid to products and sustainability, a good innovative strategy is the element that cannot be missing in a successful company. Moreover, for a better future in the food industry, a way of making sustainable innovation based on the increase of new nanotechnologies and the development of biotechnologies should be proposed.

As a future development of the study, case studies should be investigated in order to, on the one hand, confirm the results of this study, and on the other hand, to provide insights on the same results.

\section{References}

Aguilera, J.M. (2006). Seligman Lecture 2005: food product engineering: building the right structures. Journal of the Science of Food and Agriculture 86, 1147-1155.

Alarcón, S., \& Arias, P. (2018). The public funding of innovation in agri-food businesses. Spanish J. Agric. Res. 16(13), 2018164-12657.

Bayona-Saez, C., Cruz-Cázares, C., García-Marco, T., \& García, M. S. (2017). Open innovation in the food and beverage industry. Management Decision. 
Bigliardi, B. (2019). Open innovation and traditional food. In Innovations in traditional foods (pp. 85-99). Woodhead Publishing.

Bigliardi, B., \& Galati, F. (2013). Models of adoption of open innovation within the food industry. Trends in Food Science \& Technology 30(1), 16-26.

Bigliardi, B., \& Galati, F. (2016). Open innovation and incorporation between academia and food industry. In Innovation Strategies in the Food Industry (pp. 19-39). Academic Press.

Bigliardi, B., Bottani, E., \& Galati, F. (2010). Open innovation and supply chain management in food machinery supply chain: a case study. International Journal of Engineering, Science and Technology 2(6).

Bigliardi, B., Ferraro, G., Filippelli, S., Galati, F. (2020). The past, present and future of open innovation. European Journal of Innovation Management, doi: 10.1108/EJIM-10-2019-0296.

Bigliardi, B., Galati, F., \& Pavesi, F. (2019). How open is the food NPD process? Preliminary results from an explorative study. International journal of entrepreneurship and innovation management 23(3), 229-245.

Bossle, M.B., De Barcellos, M.D. and Vieira, L.M. (2016). Why food companies go green? The determinant factors to adopt eco-innovations. British Food Journal 118(6), 1317-1333.

Bresciani, S. (2017). Open, networked and dynamic innovation in the food and beverage industry. British Food Journal 119(11), 2290-2293.

Caiazza, R., Volpe, T., Stanton, J. L., Griffith, C. J., Ciliberti, S., Carraresi, L., \& Bröring, S. (2016). Drivers of innovation in Italy: food versus pharmaceutical industry. British Food Journal.

Capitanio, F., Coppola, A., Pascucci, S. (2010). Product and process innovation in the Italian food industry. Agribusiness: An International Journal, 26, 503-518.

Chesbrough, H. (2003). Open innovation: the new imperative for creating and profiting from technology. Boston, MA: HBS Press.

Chesbrough, H., Vanhaverbeke, W., West, J. (2006). Open innovation: Researching a new paradigm. USA: Oxford University Press.

Choi, H. (2018). Technology-push and demand-pull factors in emerging sectors: evidence from the electric vehicle market. Industry and Innovation 25(7), 655-674.

Christensen, J.L., Rama, R., Von Tunzelmann, N. (1996). Study on innovation in the European food products and beverages industry. European Innovation Monitoring System, EIMS publication 35, European Commission, Directorate General XIII, Luxembourg.
Ciliberti, S., Carraresi, L., \& Bröring, S. (2017, June). What drives marketing and organizational innovation in the food industry? A comparison between Italy and Germany. In International European Forum, February 13-17, 2017, Innsbruck-Igls, Austria (Vol. 2017, No. 1012-2017-685, pp. 177-188).

Cillo, V., Rialti, R., Bertoldi, B., \& Ciampi, F. (2019). Knowledge management and open innovation in agri-food crowdfunding. British Food Journal.

Cook, D.J., Mulrow, C.D., Haynes, R.B. (1997). Systematic Reviews: Synthesis of best evidence for clinical decisions. Annals of Internal Medicine 126, 376-380.

Cooper , R.G. (1994). Third-generation new product processes. Journal of Product Innovation Management 11(1), 3-14.

Cooper, R.G. (2014). What's next?: After stage-gate. Research-Technology Management 57(1), 20-31.

Costa, A.I.A. and Jongen, W.M.F. (2006). New insights into consumer-led food product development. Trends in Food Science and Technology 17(8), 457-465.

Damanpour, F. and Schneider, M. (2009). Characteristics of innovation and innovation adoption in public organizations: assessing the role of managers. Journal of Public Administration Research and Theory 19(3), 495-522.

Dawson, I. K., Powell, W., Hendre, P., Bančič, J., Hickey, J. M., Kindt, R., ... \& Jamnadass, R. (2019). The role of genetics in mainstreaming the production of new and orphan crops to diversify food systems and support human nutrition. New Phytologist 224(1), 37-54.

De Martino, M., \& Magnotti, F. (2018). The innovation capacity of small food firms in Italy. European Journal of Innovation Management.

Desouza, K.C., Awazu, Y., Jasimuddin, S. (2005). Utilizing external sources of knowledge. KM Review 8(1), 16-19.

Distanont, A., \& Khongmalai, O. (2018). The role of innovation in creating a competitive advantage. Kasetsart Journal of Social Sciences.

Ekezie, F. G. C., Sun, D. W., \& Cheng, J. H. (2017). A review on recent advances in cold plasma technology for the food industry: Current applications and future trends. Trends in Food Science \& Technology 69, 46-58.

Emamisaleh, K., Rahmani, K., \& Iranzadeh, S. (2018). Sustainable supply chain management practices and sustainability performance in the food industry. The South East Asian Journal of Management.

Enkel, E., Gassmann, O., Chesbrough, H. (2009). Open R\&D and open innovation: exploring the phenomenon. $R \& D$ Management 39, 311-316. 
Franceschelli, M. V., Santoro, G., \& Candelo, E. (2018). Business model innovation for sustainability: a food start-up case study. British Food Journal 12(10), 2483-2494.

Galati, F., Bigliardi, B., \& Petroni, A. (2016). Open innovation in food firms: Implementation strategies, drivers and enabling factors. International Journal of Innovation Management 20(03), 1650042.

Galati, F., Bigliardi, B., Petroni, A., Petroni, G., Ferraro, G. (2019). A framework for avoiding knowledge leakage: evidence from enginnering to order firms. Knowledge Management Research \& Practice, doi: 10.1080/14778238.2019.1638736.

Garcia, M. (2011). Future R\&D strategies in food and drinks: evolution from orthodox approach to open innovation. In IFAMA Annual World Symposium, 20-21 June 2011 Frankfurt, Germany.

Godin, B. (2006). The linear model of innovation, the historical construction of an analytical framework. Science, Technology, \& Human Values 31(6), 639-667.

Grimsby, S., \& Kure, C. F. (2019). How open is food innovation? The crispbread case. British Food Journal.

Grunert, K.G., Jeppesen, L.F., Jespersen, K.R., Hansen, K., Trondsen, T. (2005). Market orientation of value chains: a conceptual framework based on four case studies from the food industry. European Journal of Marketing 39, 428-455.

He, X., Deng, H., \& Hwang, H. M. (2019). The current application of nanotechnology in food and agriculture. Journal of Food and Drug Analysis, 27(1), 1-21.

Holland, M. (1928). Research, Science and Invention. In F.W. Wile, $A$ Century of Industrial Progress, American Institute of the City of New York, New York: Doubleday, Doran and Co., 1928; pp. 312-334.

Hullova, D., Trott, P., \& Simms, C. D. (2016). Uncovering the reciprocal complementarity between product and process innovation. Research Policy, 45(5), 929-940.

Huston, L., \& Sakkab, N. (2006). Connect and develop. Harvard Business Review 84(3), 58-66.

King, T., Cole, M., Farber, J. M., Eisenbrand, G., Zabaras, D., Fox, E. M., \& Hill, J. P. (2017). Food safety for food security: Relationship between global megatrends and developments in food safety. Trends in Food Science \& Technology 68, 160-175.

Lichtenthaler, U. (2008). Open innovation in practice: an anlysis of strategic approaches to technology transactions. IEEE Transactions on Engineering Management 55(1), 148-157.

Lienhardt, J. (2004). The food industry in Europe, statistics in focus Industry, trade and services. Luxembourg: Eurostat, European Communities. 39/2004.
Long, T. B., \& Blok, V. (2018). Integrating the management of socioethical factors into industry innovation: towards a concept of Open Innovation 2.0. International food and agribusiness management review 21(1030-2018-2278), 463-486.

Majid, I., Nayik, G. A., Dar, S. M., \& Nanda, V. (2018). Novel food packaging technologies: Innovations and future prospective. Journal of the Saudi Society of Agricultural Sciences 17(4), 454-462.

Manzini, R., Lazzarotti, V., \& Pellegrini, L. (2017). How to remain as closed as possible in the open innovation era: the case of Lindt \& Sprüngli. Long Range Planning 50(2), 260-281.

Martinez, M.G. (2014). Co-creation of value by open innovation: unlocking new sources of competitive advantage. Agribusiness 30(2), 132-147.

Martinez, M.G., Briz, J. (2004). Innovation in the Spanish food \& drink industry. International Food and Agribusiness Management Review 3(2), 155-176.

Menrad, K. (2004). Innovation in the food industry in Germany. Research Policy 33(6-7), 845-878.

Mowery, D. and Rosenberg, N. (1979). The influence of market demand upon innovation: a critical review of some recent empirical studies. Research Policy 8(2), 102-153.

Myers, S. and Marquis, D.G. (1969). Successful industrial innovations: A study of factors underlying innovation in selected firms, NSF 69-17. Washington, DC: National Science Foundation, 1969.

Omta, S.W.F. and Folstar, P. (2005). Integration of innovation in the corporate strategy of agri-food companies. In W.M.H. Jongen, \& M.T.G. Meulenberg (Eds.), Innovation in agri-food systems, 2005. pp. 223-246. Wageningen: Wageningen Academic Publishers.

Price, W.J. and Bass, L.W. (1969). Scientific research and innovative process. Science 164(3881), 802-806.

Rabadán, A., González-Moreno, Á., \& Sáez-Martínez, F. J. (2019). Improving firms' performance and sustainability: The case of ecoinnovation in the agri-food industry. Sustainability 11(20), 5590.

Rama, R., Von Tunzelmann, N. (2008). Empirical studies of innovation in the food and beverage industry. R. Rama (Ed.), Handbook of innovation in the food and drink industry, Haworth Press, New York/ London. 2008.

Rauter, R., Perl-Vorbach, E., \& Baumgartner, R. J. (2017). Is open innovation supporting sustainable innovation? Findings based on a systematic, explorative analysis of existing literature. International Journal of Innovation and Sustainable Development 11(2-3), 249-270.

Saguy, I. S. (2016). Challenges and opportunities in food engineering: Modeling, virtualization, open innovation and social responsibility. Journal of Food Engineering, 176, 2-8. 
Saguy, S., \& Taoukis, P. S. (2017). From open innovation to enginomics: paradigm shifts. Trends in Food Science \& Technology 60, 64-70.

Santeramo, F. G., Carlucci, D., De Devitiis, B., Seccia, A., Stasi, A., Viscecchia, R., \& Nardone, G. (2018). Emerging trends in European food, diets and food industry. Food Research International 104, 39-47.

Santoro, G., Ferraris, A., \& Winteler, D.J. (2019). Open innovation practices and related internal dynamics: case studies of Italian ICT SMEs. EuroMed Journal of Business.

Sarkar, S. \& Costa, A.I.A. (2008). Dynamics of open innovation in the food industry. Trends in Food Science and Technology 19, 574-580.

Sodano, V. (2019). Innovation trajectories and sustainability in the food system. Sustainability 11(5), 1271.

Stanco, M., Nazzaro, C., Lerro, M., \& Marotta, G. (2020). Sustainable Collective Innovation in the Agri-Food Value Chain: The Case of the "Aureo" Wheat Supply Chain. Sustainability 12, 5642.

Stevens, R. (1941). A Report on Industrial Research as National Resource: Introduction. Research: A National Resource (II): Industrial Research, NRC, Washington, DC: USGPO, 1941.

Török, Á., Tóth, J., \& Balogh, J. M. (2019). Push or Pull? The nature of innovation process in the Hungarian food SMEs. Journal of Innovation \& Knowledge 4(4), 234-239.

Traill, W.B. and Meulenberg, M.T.G. (2002). Innovation in the food industry. Agribusiness 18(1), 1-21.
Traitler, H., \& Saguy, L.S. (2009). Creating successful: innovation partnerships. Food Technology (Chicago), 63(3).

Trott, P., \& Simms, C. (2017). An examination of product innovation in low-and medium-technology industries: Cases from the UK packaged food sector. Research Policy 46(3), 605-623.

Tsimiklis, P., Ceschin, F., Green, S., Qin, S.F., Song, J., Baurley, S., \& Makatsoris, C. (2015). A consumer-centric open innovation framework for food and packaging manufacturing. International Journal of Knowledge and Systems Science 6(3), 52-69.

Ulvenblad, P. O., Ulvenblad, P., \& Tell, J. (2019). An overview of sustainable business models for innovation in Swedish agri-food production. Journal of Integrative Environmental Sciences 16(1), 1-22.

Vrontis, D., Bresciani, S. and Giacosa, E. (2016). Tradition and innovation in Italian wine family businesses. British Food Journal 118(8), 1883-1897.

Wallin, M.W., \& Von Krogh, G. (2010). Organizing for open innovation: focus on the integration of knowledge. Organizational Dynamics 39(2), 145-154.

West, J., \& Gallagher, S. (2006). Challenges of open innovation: the paradox of firm investment in open-source software. R\&D Management 36(3), 319-331.

Wolfert, J., Verdouw, C.N., Verloop, C.M., \& Beulens, A.J.M. (2010). Organizing information integration in agri-food-A method based on a service-oriented architecture and living lab approach. Computers and Electronics in Agriculture 70(2), 389-405. 
